\title{
Too much to pay: an estimation through microsimulation techniques of the monetary costs of early school leaving in Spain
}

\begin{abstract}
Simulation techniques are nowadays widely applied in many areas of knowledge, trying to provide tools predicting future behaviors or reactions. Public economy is one of the areas paying more and more attention in last years to simulation techniques in order to evaluate the achievement of different public policies, though these techniques are not as developed as in other subjects. In this context, this paper attempts to provide empirical evidence to simulation literature, gathering two main aspects: on one hand, an extended and alarming problem in Spain, the monetary costs associated with early school leaving (Spain's ESL rate stands at more than 30\%, making it one of the highest in the EU); and on the other, a not very common methodology to approach this phenomenon: microsimulation techniques. Specifically, a behavioral microsimulation model is proposed in order to study the effects on employment and wages of eradicating early school leaving in Spain over a twenty-year time horizon. Our results, under various scenarios, indicate that an increase in GDP of between 4 and $17 \%$ could be achieved.
\end{abstract}

Keywords: Education, econometrics, public expenditure, statistics, behavior.

JEL codes: C.15, I.240, I.250. 


\section{Introduction}

This article seeks to estimate the monetary costs associated with early school leaving (henceforth ESL) in Spain, using microsimulation techniques for that purpose. The added value of this article relies, on one hand, on the importance of determining the monetary costs of ESL, and on the other, on the simulation approach we use, not as usual in social sciences as in other areas of knowledge, related to computing or labs research. The studied phenomenon, ESL, has monetary (as well as non-monetary) costs for individuals and society alike, and their calculation is essential for guiding decision makers in their efforts to identify the correct policies for an area where most of the investment is made by the public sector. We should stress from the outset that the scale of ESL in Spain is of particular concern: $31 \%$ of Spaniards aged between 18 and 24 in 2007 had dropped out of the education system having completed, at most, lower secondary education.

The medium and long-term future of these young people is less promising than that of those who decide to enroll in post-compulsory education: numerous studies conclude that the income of those who drop out of the education system prematurely is lower, that they have a higher probability of being unemployed, marginalized or involved in criminal activity, and a greater likelihood of finding themselves in a worse state of health and of enjoying lower rates of personal satisfaction. However, it is not just the individuals who suffer the negative consequences of this decision, but the country as a whole. A high proportion of poorly trained individuals has considerable repercussions: the taxable income that they generate is obviously lower, while their public expenses (for services such as healthcare, justice, unemployment benefits, etc.) 
are greater. What's more, the country also suffers general losses in terms of unemployment, productivity and growth.

Policy makers are aware of the need to tackle this problem and to reduce the proportion of young people who drop out of education prematurely. One of the primary goals fixed by the Council of the European Union (2009) is to reduce the ESL rate among its member states to $10 \%$ by 2020 . By so doing, a direct impact on equity, social cohesion and active citizenship is expected to be achieved, as long as it would allow all citizens to incorporate within lifelong learning programs.

The analysis of the costs associated with the fact that some individuals do not attain a sufficient level of education to enable them to progress adequately either as individuals or in society has received little attention in Europe. As we shall see below (section 3), this line of research has attracted considerable interest in English-speaking countries, most specifically in the US, Canada and Australia. By contrast, in nonAnglophone European countries few studies have been undertaken, as Psacharopoulos (2007) has pointed out. In particular, in the case of Spain no one, to date, has specifically sought to quantify the costs of ESL. Besides, microsimulation techniques provide a very interesting research line, arising in the field of economic analysis of public expenditure policies.

Thus, there are three factors that make this subject particularly worthy of our attention: first, the very high levels of ESL in Spain; second, the concern being shown by both national and European bodies for this problem; and, finally, the lack of analyses undertaken to date in non-Anglophone countries.

The rest of this article is structured as follows. In section 2 we review the problem of ESL in Spain, and draw comparisons with the situation in the rest of Europe. Section 3 is dedicated to reviewing the methodologies and results of studies that have 
calculated the monetary costs of ESL. The methodology and the data used in our empirical analysis are presented in section 4 . In section 5 we present and discuss the results obtained. Section 6 concludes and examines the implications of the study.

\section{Early school leaving in Spain}

In this article we use the definition of early school leaving employed by the European Commission: the share of the population aged between 18 and 24 with at most lower secondary education and not in further education or training. In Figure 1, we see that, despite the fact that almost all countries reduced their ESL figures between 2000 and 2007, most are still some distance from the goal of $10 \%$ fixed by the EU for 2020 . The case of Spain is particularly striking, not only because of its high rates of ESL (around $30 \%$ ), but also because it is one of the few countries in which the ESL rate increased between 2000 and 2007. As can be seen in Figure 1, only Portugal, Malta and Turkey have figures higher than Spain's. Moreover, while the ESL rate in Spain fluctuated between 1996 and 2006, the values never varied greatly from 30\%.

\section{Insert Figure 1 here}

The comparatively high incidence of ESL in Spain is explained in part by the low level of educational attainment of the previous generation but also, among other factors (see, Calero, 2008), by the low wage returns to post-compulsory education in comparison to other European countries. This means that the incentives to invest in higher levels of education are not as great. This characteristic of the Spanish job market has come to the attention of OECD experts, who highlighted this weakness in the Economic Survey of Spain 2008 (see, OECD, 2008).

We conclude this section by highlighting the consequences of ESL on employment patterns in Spain. Activity rates of early school leavers are lower; 
moreover, their risk of unemployment is considerably higher: in 2009, there was a ninepercentage point gap between the respective risk of unemployment of an individual with post-compulsory secondary studies and that of an early school leaver.

\section{Literature review}

\subsection{Microsimulation in economics sciences}

In economic sciences, microsimulation is defined as a set of microeconomic techniques aiming to predict changes in some economic events. In public economics, the potential of this methodology relies on the possibility of evaluating the impact of a shift in a policy, without really performing it. In this field, main work with microsimulation has been done in tax evaluation ${ }^{1}$, not so much on the expenditure side (education ${ }^{2}$, health, justice, pensions, unemployment transfers, etc.).

Microsimulation in economics requires some elements: a good micro database, containing enough information about the unit of analysis (in this case, usually citizens); an econometric model providing these individuals behavior; the predictions resulting from this model; and, of course, the policies which are to be changed and evaluated.

\footnotetext{
${ }^{1}$ Choi (2011) provides a good survey of references, both for tax and expenditure simulations, as well as a classification of models of microsimulation.

${ }^{2}$ The articles of Gertler and Glewwe (1990), Ferreira and Leite (2002), Todd and Wolpin (2002), Bourguignon and Ferreira (2003), Attanasio, Costas and Szekely (2003), De Pablos and Gil (2008) or Choi (2011) are some examples of different applications of microsimulation techniques in the field of education economics, the policy we analyze in this paper.
} 
Once the changes are applied, some other aspects can be analyzed, such as the resulting income distribution, winners and losers of the reform, changes in welfare, etc.

\subsection{Evidence on the costs of early school leaving}

As mentioned above when outlining the objectives of this paper, there are important reasons as to why a study of the costs of early school leaving is of interest. English-speaking countries, with the US at their head, aware of the need to determine the losses attributable to early school leaving, have conducted numerous studies analyzing and quantifying the magnitude of this phenomenon. In Europe this line of research is not yet fully developed, while in Spain we are unaware of any study that seeks to estimate the costs of early school leaving.

The origins of this line of research can be traced back to the early seventies in the US, when its Senate commissioned a pioneering study by Henry Levin (1972). This report undertook the first estimate of the costs to the nation of the failure to attain a minimum of high school completion, focusing on lifetime income losses and on the burden to the nation of increased welfare expenditure and the costs of crime, reduced political participation and intergenerational mobility.

Adopting a similar line to that taken in Levin's (1972) report, various studies conducted by different US institutions and researchers-, have examined this question from a range of perspectives and provide us with a more complete picture of the issues at stake. The main findings highlight these numbers: in the US, a loss of $1.6 \%$ of the GDP in income and taxes for each cohort of 18-year-olds who never complete high school in the US (Levin et al. 2006, 2007); furthermore, savings of 4.9 thousand million dollars in costs related to violence (Vernez et al., 1999) or 17 thousand million dollars in medical expenses, if all individuals managed to graduate from high school (Alliance for Excellent Education, 2006). In Australia, a decrease of 50\% of ESL would mean an 
increase in GDP of $0.28 \%$ by 2020, $1.1 \%$ by 2040 (Allen Consulting Group, 2003). In Canada, the Canadian Council on Learning (2009) estimates private costs in terms of annual earnings of 3,491 dollars for each student that drops out, costs that reach 104,222 dollars if they are extended throughout an individual's lifetime. Similarly, the losses in tax income and unemployment payments amount to 11.5 and 6.1 thousand million dollars, respectively.

\section{Methodology and data}

\subsection{Methodology}

The idea underlying this estimation of the monetary costs of early school leaving can be succinctly summed up in the following question: what would the monetary effects be if early school leaving were fully eliminated in Spain? In seeking to answer this question, we aim to compare the real situation (in which the ESL rate stands at around 30\%) with a hypothetical situation in which ESL is eradicated completely. By comparing the two situations we will be able to determine the individual and social costs associated with ESL, since we estimate the losses associated with a scenario in which some individuals have very low levels of educational attainment. And given that we are interested in estimating the monetary costs, the perspective that we take is one that is related to the labor market, studying the changes in individuals' wages and rates of employment over a twenty-year period in which ESL is eliminated.

To do this, we propose a methodology that is applied in four separate phases: in the first two, a prior econometric study is undertaken, which is necessary for the 
following phases, in which the hypothetical situation is simulated and the monetary costs of ESL are estimated.

The first of these phases seeks to estimate the determinants of the educational choices open to a 16-year old. Up to this age, education in Spain is compulsory. However, the law allows students to repeat up to two academic years and remain in compulsory secondary education (the ordinary system) until the age of 18 and the end of the academic year. But it is also possible that some students of 16 or more do not manage to complete compulsory secondary education (known as Educación Secundaria Obligatoria or ESO in Spain), which means they abandon the education system with no other qualification than that awarded at the end of primary education. If before the age of 25 these individuals do not return to the education system, they will be added to the ESL statistics, constituting the group in the worst relative position as a result of their having the lowest possible level of educational attainment. Once ESO has been completed, students are faced with having to make a new decision: to continue studying in post-compulsory secondary education or to abandon their studies altogether. This last option also falls under the definition of ESL. In this instance, the youngsters can enter the job market, or remain unemployed and inactive. Finally, those who complete postcompulsory secondary education face a third decision: leaving the education system (which would not now be considered as ESL, since the individual would have completed post-compulsory secondary studies), or embarking on studies in higher education. 
We model this succession of educational choices in phases using a doublehurdle model ${ }^{3}$, in which we estimate the probabilities of young Spaniards between the ages of 16 and 23 (individuals who are theoretically able to continue studying) taking each of the aforementioned decisions. In other words, we study the factors that determine the likelihood of each individual choosing each of the educational opportunities as opposed to the option of dropping out of the educational system. The model used is known as a double-hurdle model because successive choices have to be made that are dependent on the earlier decisions and, moreover, in each stage the population of individuals is reduced, and that is why sample selection must be taken into consideration. For example, a student cannot choose to study post-compulsory education if he or she has not completed compulsory secondary education. To conduct all the likelihood estimates, we use discrete choice probit models ${ }^{4}$, in which the dependent variable captures the option in which the individual chooses/completes or not each of the levels of education. The literature on this question is extensive (see, for example, Dronkers, 2008) and confirms that there are a range of socioeconomic and cultural factors (including household income, the level of education or job situation of other family members, the job market situation, etc.) that have a decisive impact on the educational choices made by an individual.

Having modeled the behavior in terms of the educational decisions of young Spaniards that are theoretically of an age to be studying, in the second phase we analyze the effects of eliminating ESL on this age group. Clearly such a situation would result in major changes to the education system and the job market. Individuals who previously

\footnotetext{
${ }^{3}$ For a detailed theoretical and applied explanation of the double-hurdle model, see Dubin and Rivers (1990).

${ }^{4}$ See Greene (2008) for a review of discrete choice models.
} 
dropped out of the education system had basically two options: to enter the job market as workers or to remain unemployed. Under the scenario in which ESL is eradicated, these young people would be forced to leave the job market or their situation of unemployment or inactivity and return to the education system. Thus, in the best of cases, they would have to forego their wages. As a result, the job market would undergo a transitory reduction in the number of the least qualified workers during the early years of the process of reducing the ESL rate. Going one step further, we can then consider what would happen if this situation (the elimination of ESL) were to evolve in subsequent years. Fixing a twenty-year period so that the assumptions are not subject to excessively unpredictable changes: what would the monetary benefits be for society of having a better stock of human capital? How would this situation be reflected in the job market? To answer these questions we establish three age bands (in addition to the first that includes individuals, potential students, aged 16 to 23), whose wage and employment profiles will predictably be quite different, given that they are individuals at different points in their life cycle:

- Band 2: ages ranging from 24 to 37 . This band ends twenty years after individuals have potentially obtained a post-compulsory secondary education qualification at the age of 18 .

- Band 3: ages ranging from 38 to 42 . This band ends twenty years after individuals have potentially obtained a higher education qualification at the age of 23 .

- Band 4: ages ranging from 43 to 65 . Terminates with retirement.

In applying the above approach, in this second phase we need to estimate the wage equations for individuals in order to identify the determinants of their earning a 
higher or lower wage. Human capital theory has examined this question in depth by studying the wage returns associated with investment in education. The "Mincer equation" (Mincer, 1974) has traditionally been used to determine the extent to which the wage earned by an individual depends on his or her level of education and work experience. Successive contributions to the Mincer equation have helped perfect the original econometric specification, so that in this study we take into consideration, among other improvements, the incorporation of the selection bias. This involves differentiating between individuals in a situation of unemployment or inactivity (those that do not receive a wage) and workers (those that do receive one), so that the Mincer equation is only applied to those that are in employment. The usual solution adopted in correcting this problem is the use of Heckman's two-step estimator (1979). In the first stage, this model involves estimating the probability of an individual being employed or not, normally using a logistic regression $\operatorname{model}^{5}$. In the second stage of the model, and only for those in employment, we estimate the wages equations using Ordinary Least Squares, as a function of a set of factors (in addition to education and experience) that might affect this determination. This model is applied to each of the four age bands.

Next, in the third phase the simulation exercise itself is conducted, which enables us to compare the real situation, in which the phenomenon of ESL exists, with a series of hypothetical situations that describe different scenarios under which ESL does not exist: specifically, a new distribution is considered of these individuals in their different age bands (which express the evolution taken by those youngsters who stopped dropping out of the education system prematurely) with new levels of educational

\footnotetext{
${ }^{5}$ For a review of studies on educational returns with Mincer equations and Heckman's selection estimation, see, among others, Willis and Rosen (1979) and Mulligan and Rubinstein (2008).
} 
attainment. Accordingly, all individuals with primary and secondary education would pass to the next level in the system, that is, post-compulsory secondary studies.

Additionally, and so as to take into consideration the possible evolution in future wage premiums, we propose two alternative scenarios:

- Under the first of these scenarios, we assume that the wage premium does not change with respect to the situation in 2007. In other words, it is assumed that the increase in demand for qualifications in education compensates the simulated increase in the supply of these qualifications. Therefore, it is supposed that the education returns to the demand factors remain unaltered. We refer to this outcome as the constant scenario.

- Under the second scenario, we assume that the wage premium shifts in favor of the wages of the most highly qualified, assuming that the increase in demand for qualifications in education more than compensates for the simulated increase in the supply of these qualifications. Under this scenario we estimate increases of 10 and $20 \%$ in the education returns of individuals with post-compulsory education and higher education, respectively. The justification for the plausibility of this scenario is provided by the possibility of a future intensification in the demand for higher qualifications in the job market, an intensification that is coherent with the long-term historical trend. We refer to this outcome as the augmented scenario.

Having established our assumptions and the simulated scenarios, the parameters obtained in the models resulting from the calculation of the wage equations and the rates of employment (obtained in the earlier stages) are used as our starting point or the real situation. Thus, the simulation itself involves recalculating these wages and rates of 
employment, incorporating the new educational endowment of the individuals according to their level of education under the simulated situation (without ESL) and under the two scenarios in the evolution of the wage premium.

Finally, in the fourth phase, we quantify the effect on the GDP of the simulated changes in the aggregate remunerations for a period of time twenty years in the future.

\subsection{Data, sample and variables}

In this analysis we use data for Spain for the year 2007 drawn from the European Union Statistics on Income and Living Conditions (henceforth EU-SILC). This survey, addressed to households and their members aged 16 and over, examines many different aspects of the population's living conditions and includes the information required to undertake the analysis proposed here.

The data from the EU-SILC serve as the basis for the analyses conducted in the first two phases of our study, although the samples used in each differ. In the first phase, in which we analyze the determinants of individuals' educational choices after the age of 16 , we take a subsample comprising 3,115 young people between the ages of 16 and $23^{6}$ (both inclusive $^{7}$ ). Of these, 2,860 are aged between 18 and 24 (the ages used in defining ESL). In the second phase, in which we estimate the wage equations, we use a

\footnotetext{
${ }^{6}$ The fixing of the age bands in later sections of this study makes it necessary in this first part to establish as our subsample individuals aged between 16 and 23, which means that this age band does not coincide exactly with that used in the definition of ESL, which ranges from 18 to 24 .

${ }^{7}$ This age band can be considered to include the theoretical ages of demand for education, bearing in mind that that the age for completing higher education can often exceed the theoretical age for graduating (21 to 22) for various reason: repeating an academic year, postgraduate studies, longer degree courses in some subjects, etc.
} 
subsample comprising 22,560 individuals aged between 16 and 65 (given that the latter is the theoretical age of retirement in Spain).

We next choose the variables for the econometric models (corresponding to the first two phases), which are determined, on the one hand, by the availability of questions in the EU-SILC that are appropriate to our needs and, on the other, by attempting to include those proposed in the literature for an estimation of this type. Thus, for the first model we select variables that capture the factors that determine demand at each level of education, emphasizing those that might affect the decision to drop out of the education system prematurely. Thus, we consider personal variables capturing aspects of the household of origin and the job market. In the second model, the variables are determined above all by the proposals noted in earlier studies ${ }^{8}$, in other words, education, work experience and other factors that might affect either employment or wages ${ }^{9}$.

\section{Results and discussion}

As described above in the theoretical discussion, the first results are derived from the estimation of the education demand models of each individual for each level of education: compulsory, post-compulsory and higher.

\footnotetext{
${ }^{8}$ Among others, though by no means an exhaustive list, see Arrazola et al. (2001), Salas (2004), Navarro et al. (2001), Calero (2002), Barceinas et al. (2002).

${ }^{9}$ Due to lack of space, information about the dependant and independent variables considered in each model, so as the results of the models (Mincer wage equations and demand for education), may be provided under request to the authors.
} 
The estimated models are shown in Table III in the Appendix. Each model is robust having been corrected for heteroskedasticity using the Huber-White procedure. The fit is good, according to all the measures of goodness of fit presented. The models are globally significant, as shown by the likelihood ratio test (Wald chi-squared test). The results show that there are certain factors that determine the demand for each of the educational levels in a similar measure, and which coincide with those typically reported in the literature. Thus, the level of education attained by the mother is a key determinant of a child seeking to enter a certain level of education, as opposed to dropping out of the education system. Moreover, the higher the level of education attained by the mother (post-compulsory or higher studies), the greater is the probability that her son or daughter will seek to enter post-compulsory or higher education. By contrast, the presence of younger siblings or a high percentage of unemployed in the household have a negative effect on the probability of remaining in the education system. In the first of these cases, this would seem to reflect the negative influence of the higher economic costs that a household has to face by having to maintain younger children, while in the second, it would show a youngsters' preference for the job market owing to the need to contribute economically to the household. Finally, the effect of some variables differs between the educational levels analyzed: thus, household income has a positive effect, albeit limited to the fact of completing compulsory and postcompulsory education, while the fact of being a woman has a positive effect on the likelihood of demanding higher education.

Next, we estimate the Mincer equations. Table IV in the Appendix shows the results of estimating the wage returns for the four age bands. As is shown by the goodness of fit measures, the fit of all the models is good, all being robust to heteroskedasticity and globally significant. Recall that the first age band (16- to 23-year 
olds) corresponds to individuals that are of a potential age for still being in education. Therefore, this group turns out to be quite different when calculating their wage returns, as many of the individuals will not be in the job market (only $32.64 \%$ of those in this age group work) and a high proportion of them are still within the education system and do not participate in the labor market. In fact, this is the only age band for which no sample selection was found to exist when estimating the wage equations, so it is the only case in which an estimation was not made in two phases (probability of being employed in the first phase and estimation of the wage equation in the second).

Our results show that, for young workers between the ages of 16 and 23, the sole fact of having attained a higher education seems to have a significant and positive effect on wages. This implies that young people with secondary education (lower or higher stages) do not earn significantly different wages from those earned by individuals that have only attained a primary level of education. As expected, the number of years of work experience results in higher wages, although the effect is not very marked in this age group. For the other age bands we observe, on the one hand, that the factors which affect the likelihood of being employed coincide almost exactly with those that determine wages, and on the other, that the profile of the variables that explain wages are very similar in the different age bands, above all in the case of the second and third groups, and with some variations in the case of the final age band (ages 42 to 65). For individuals aged 24 to 37 and 38 to 42, we observe that having higher levels of education (and above all, graduating in higher education) are reflected in higher wages and a greater likelihood of employment. Work experience also has a positive effect, although there is a depreciation in human capital, confirming the parabolic relationship between income and experience: as the number of years of work experience increases, his or her income increases too, reaching a maximum wage at a certain point in their 
lifecycle, and from this moment on, income begins to fall. In addition, living in regions with higher income per capita levels has a positive effect on wage earning. Finally, we note that for the oldest individuals the profile is subject to a slight change: while higher levels of educational attainment are reflected in better wages, experience no longer appears to be so important when explaining wage levels.

Based on these results, Table I shows the quantification of the impact on wage returns associated with each of the levels of education, calculated in relation to the attainment of a primary level of education. In general, the results reveal positive wage premiums, which shows that the attainment of higher levels of education (above all, higher education itself) is reflected in better wages. By age bands, as well as the positive impact of education on wages, we note that the cohort of oldest individuals (ages 43 to $64)$ is the one with the greatest wage premium for all levels of education. Finally, for the first age band, there are negative returns associated with having completed ESO compared with having attained primary education and a wage premium that is virtually zero in the case of the third age group, which shows the negative (or virtually zero, respectively) impact on wages of having completed this level of education.

\section{Insert Table I here}

Having estimated the factors that affect the demand for education and wage levels, we are now in a position to use this information to carry out the simulation exercise described in the theoretical section. In this third phase we calculate the differences between real and simulated situations, which we describe in terms of wage and employment changes, showing the variations in average monthly wages, and these variations differentiated by sex and educational attainment.

The simulation results show that the elimination of ESL has positive effects for both microeconomic (i.e. for individuals) and macroeconomic (i.e. for society as a 
whole) levels. Specifically, the aggregate income derived from the wages of the employees undergoes a marked increase with respect to the initial situation (varying from $10 \%$ in the worst of cases to $74.6 \%$ in the best). Moreover, as shown by column 1 in Figures 2 and 5, we see that, in general terms, the average monthly wages of individuals increase, as an effect of the increase in the educational endowment of the population analyzed under both scenarios. This impact increases as we move up the age bands and it is even greater when the wage premium changes benefit the most highly qualified (scenario 2). Furthermore, there is an increase in the average employment rate when eliminating ESL in both scenarios (column 1 in Figures 2 and 5). This supposes that, due to their higher levels of education, some individuals have been able to change their labor situation, thus escaping unemployment and inactivity. As a result, and due to the increase in the employment rate after the elimination of ESL, these individuals would also contribute to the increase in aggregate wages, given that under the new situation they would become wage earners.

If we disaggregate the results according to certain individual characteristics (columns 2 to 5 in the figures), the most notable result is the marked improvement enjoyed by women. Their incorporation within the job market results in a significant increase in their wage levels. The fundamental cause of this result would appear to lie in the large increase observed in the female employment rate. By level of education, the elimination of ESL (and therefore, of individuals with only primary and secondary education) represents a reduction in the rates of employment for individuals with postcompulsory secondary education in favor of individuals with higher education.

However, both groups enjoy wage increases, above all when the wage premium is altered in favor of the most qualified individuals. Yet, and although when breaking down the results according to certain individual characteristics we note some reductions 
in mean wages and rates of employment in some of the categories or age bands, the general trend shows major improvements in both indicators following the elimination of ESL. The best results are found in the fourth age band under the most optimistic scenario (scenario 2), which confirms the positive impact of the elimination of ESL in the future.

\section{Insert Figures 2 to 5 here}

To complete the estimation of the monetary impact of ESL in Spain, in the last stage of the study we quantify the effect on GDP of the simulated changes in aggregate wages (Table II), evaluating this effect at a point twenty years from the base year of the analysis, i.e. 2007. That is, we considered the improvements in annual aggregate wages for a set comprising the first three age bands. Our results show that the elimination of ESL leads to a marked increase in these wages, ranging between 4 and $17 \%$ with respect to the GDP depending on various assumptions. This percentage of GDP is, as such, the monetary cost of the wage losses attributable to ESL.

\section{Insert Table II here}

\section{Conclusions}

The goal of this article has been the identification and quantification of the monetary costs of early school leaving in Spain, using microsimulation techniques, an arising and promising line of research in public economic evaluation. Although ESL has a wide range of negative repercussions for the individual and the whole of society alike, many of them non-monetary, we have limited this study solely to those repercussions that result in direct monetary losses. We should, therefore, stress that our cost estimations are necessarily an underestimation of the total impact of ESL, since they do not include 
the costs attributable to these non-monetary effects.

The constantly high ESL figures recorded in Spain (around 30\% over the last decade, while the target fixed by the EU for 2020 stands at just 10\%) and the general absence of studies that estimate the associated monetary costs in non-English speaking countries serve to emphasize the importance of the objective set in this article as regards education policy.

The methodological approach adopted has been that of microsimulation. In the first phase, and before conducting subsequent estimations, we have estimated the determinants of the educational choices open to a youth of 16 in Spain. An understanding of the determinants of educational demand furnishes information for the microsimulation analysis that we then undertake, and in which we focus on the effects on the job market, specifically, on the employment rate and on wage levels.

The estimation of the simulated situation is conducted using wage equations; given that there exists a selection bias (those without employment do not receive a wage), we first need to estimate the probability of being employed. In this way we obtain information about the factors affecting the probability of being employed and wage levels. As expected, our results show the positive effects on wages and on the probability of being employed of having completed higher levels of education, of having greater work experience (although they also show a depreciation in human capital), and of living in regions with a higher per capita income.

Next we undertook a simulation exercise, which allowed us to compare a real situation, in which the phenomenon of ESL was present, with a series of simulated situations that included various scenarios in which we suppose that all individuals attain a level of education equal to or higher than higher secondary. For different age bands which reflect the evolution of students that stop dropping out of education prematurely 
- we establish two alternative scenarios that capture two possible wage premiums (constant and augmented). The differences between the real and simulated situations are described in terms of wage and employment differentials. The simulated change has a positive aggregate effect on the two indicators.

Finally, we quantified the effect on GDP of the simulated changes in aggregate remunerations, evaluating this effect at a point twenty years from the base year of the analysis, i.e. 2007. Our results show that the elimination of ESL represents a marked increase in these remunerations, an increase that ranges between 4 and $17 \%$ of GDP depending on various assumptions. This percentage of GDP is, as such, the monetary cost of the wage losses attributable to ESL.

Since 2008, the economic crisis has led to reductions in the opportunity costs of post-compulsory education in Spain and, not unexpectedly, to a certain autonomous reduction in the rates of ESL. However, the existence of such high monetary costs as those estimated in this study highlight the need to intensify educational policies aimed at reducing ESL.

\section{References}

Allen Consulting Group (2003). The Economy-Wide Benefits of Increasing the Proportion of Students Achieving Year 12 Equivalent Education: Modelling Results. Sydney, Australia.

Alliance for Excellent Education (2006). High school dropouts cost the U.S. billions in lost wages and taxes. Extraído el 10/10/2011, de www.all4ed.org/files/HighCost.pdf

Applied Research Branch, Strategic Policy, Human Resources Development Canada (2000). Dropping out of High School: Definitions and Tools. R-01-1E, Canada.

Arrazola, M., De Hevia, J., Risueño, M. y Sanz, J.F. (2001). A proposal to estimate human capital depreciation: Some evidence from Spain, Hacienda Pública Española/ Revista de Economía Pública, 172-(1/2005), 9-22. 
Barceinas, F., J. Oliver, J. L. Raymond y J. L. Roig (2002). Rendimientos de la educación y efecto tratamiento. El caso de España, Moneda y Crédito: Revista de Economía, 215, 43-68.

Belfield, C. y Levin, H.M. (2007). The Price We Pay. Economic and Social Consequences of Inadequate Education. Washington: Brookings Institution Press.

Calero, J. (2008). What happens after compulsory education? Problems of continuity and possible policies in the case of Spain, The Social Science Journal, vol. 45, n. 3, 440-456.

Canadian Council on Learning (2009). No "drop" in the bucket: the high costs of dropping out, Lessons in learning. Canada.

Council of the European Union (2009) Council conclusions of 12 May 2009 on a strategic framework for European cooperation in education and training. 'ET 2020', 2009/C 119/02.

Dronkers, J. (2008). Education as the backbone of inequality. European education policy: constraints and possibilities. En F. Becker et al. (Eds.) Social Democracy and Education. The European Experience. Amsterdam: Friederich Ebert Stiftung / Karl Renner Institut / Wiardi Beckman Stichting.

Dubin, J. A. and Rivers, D. (1990). Selection Bias in Linear Regression, Logit and Probit Models, Sociological Methods and Research, 18, 360-390.

Eurostat (2007). European Union Statistics on Income and Living Conditions, Data and Metodology. Eurostat, 2007.

Green, W.H. (2008) Econometric Analysis, Prentice Hall, 7th Edition.

Halvorsen, R. y Palmquist, R. (1980). The Interpretation of Dummy Variables in Semilogarithmic Equations, American Economic Review, 70, 474-475.

Heckman, J. J. (1979). Sample Selection Bias as a Specification Error, Econometrica, vol. 47, 153-162. Levin (1972). The Cost to the Nation of Inadequate Education. Select Senate Committee on Equal Education Opportunity, $92^{\text {nd }}$ Congress. Government Printing Office.

Levin, H.M., Belfield, C.R., Muennig, P. y C.E. Rouse (2006). The Costs and Benefits of an Excellent Education for America's Children, Technical Appendix. Teachers College, Columbia University. Levin, H.M., Belfield, C.R., Muennig, P y C.E. Rouse (2007). The Costs and Benefits of an Excellent Education for America's Children, Overview. Teachers College, Columbia University.

Ministry of Education (2009). Datos y cifras de la educación 2010. Madrid, 2010.

Mincer, J. (1974). Schooling, experience and earnings. Columbia University Press, New York.

Mulligan, C.B. y Rubinstein, Y. (2008) Selection, Investment, and Women's Relative Wages Over

Time, The Quarterly Journal of Economics, MIT Press, vol. 123(3), 1061-1110.

Navarro, M. L., Caparrós, A., Marcenaro, O. D., y Gamero, C. (2001). Un análisis comparativo del rendimiento de la educación en España. X Jornadas de la Asociación de la Economía de la Educación / coord. por Juan Gómez García, 321-334.

OECD (2008) Economic Survey of Spain, 2008. Paris (OECD).

Psacharopoulos, G. (2007). The Costs of School Failure a Feasibility Study. Analytical Report for the European Commission prepared by the European Expert Network on Economics of Education (EENEE). 
Reymer, M. y Smink, J. (cords.) (2005). Information about the School Dropout Issue: Selected Facts \& Statistics. Publication of the National Dropout Prevention Center/Network (USA).

Rouse (2007). Consequences for the Labor market. En BELFIELD, C. y LEVIN, H.M. (2007). The Price We Pay. Economic and Social Consequences of Inadequate Education. Washington: Brookings Institution Press, 99-124.

Salas, M. (2004). Rendimientos privados de las inversiones en educación superior a partir de ecuaciones de ingresos, Hacienda Pública Española / Revista de Economía Pública, 169-(2/2004), 87-117.

Vernez, G., R. Krop y C. P. Rydell (1999). Closing the Education Gap - Benefits and Costs. RAND Corporation.

Willis, R.J. y Rosen, S. (1979). Education and Self-Selection, Journal of Political Economy, University of Chicago Press, vol. 87(5), 7-36.

Gertler, P. and Glewwe, P. (1990). The willingness to pay for education in developing countries: Evidence from rural Perú. Journal of Public Economics, 42:3, pp. 251-75.

Ferreira, F. H. G. and Leite, P. G. (2002). Educational expansion and income distribution: A micro-simulation for Ceará. Texto para Discussao n 456. PUC Rio de Janeiro.

Todd, P. and Wolpin, K.I. (2002). Using a social experiment to validate a dynamic behavioral model of child schooling and fertility: Assessing the impact of a school subsidy program in Mexico. University of Pennsylvania, Population Studies Center: Philadelphia.

Bourguignon, François y Francisco H. G. Ferreira. (2003). Ex ante evaluation of policy reforms using behavioral models, in The impact of economic policies on poverty and income distribution. François and Pereira da Silva Bourguignon, Luiz A. ed. Washington DC: World Bank y Oxford University Press.

Attanasio, O., Costas, M. and Szekely, M. (2003). Using randomised experiments and structural models for "scaling up": Evidence from the PROGRESA evaluation. Institute of Fiscal Studies Working Papers, 03:05.

De Pablos, L. and Gil Izquierdo, M. (2008). Análisis de la incidencia de reformas en el sistema de financiación de la educación universitaria en España a partir de un modelo de comportamiento. Hacienda Pública Española/ Revista de Economía Pública, 184:1, pp. 117-52.

Choi de Mendizábal, Á. B. (2011) Análisis de políticas educativas de la República de Corea: Una aproximación a través de técnicas de microsimulación. Civitas. Navarra. Spain. 